\title{
Inhibition of MUC1-C Increases ROS and Cell Death in Mouse Embryonic Stem Cells
}

\author{
Jeong-A Park ${ }^{1,2}$, Sangkyu Park ${ }^{1,2}$, Jun-Kyu Choi ${ }^{1}$, Myung-Kwan Han ${ }^{3}$, Younghee Lee ${ }^{1,2}$ \\ ${ }^{1}$ Department of Biochemistry, College of Natural Sciences, Chungbuk National University, Cheongju, Korea \\ ${ }^{2}$ Biotechnology Research Institute, Chungbuk National University, Cheongiu, Korea \\ ${ }^{3}$ Department of Microbiology, Chonbuk National University Medical School, Feonju, Korea
}

\begin{abstract}
Background and Objectives: Embryonic stem (ES) cells have the capacity to self-renew and generate all types of cells. MUC1-C, a cytoplasmic subunit of MUC1, is overexpressed in various carcinomas and mediates signaling pathways to regulate intracellular metabolic processes and gene expression involved in the maintenance of cancer cells. However, the functional role of MUC1-C in ES cells is not well understood. In this study, we investigated the role of MUC1-C on growth, survival, and differentiation of mouse ES (mES) cells.

Methods and Results: Undifferentiated mES cells expressed the MUC1-C protein and the expression level was decreased during differentiation. Inhibition of MUC1-C, by the specific inhibitor GO201, reduced proliferation of mES cells. However, there was no prominent effect on pluripotent markers such as Oct4 expression and STAT3 signaling, and MUC1-C inhibition did not induce differentiation. Inhibition of MUC1-C increased the G1 phase population, decreased the S phase population, and increased cell death. Furthermore, inhibition of MUC1-C induced disruption of the ROS balance in mES cells.

Conclusions: These results suggest that MUC1-C is involved in the growth and survival of mES cells.
\end{abstract}

Keywords: Mouse embryonic stem cells, MUC1-C, Proliferation, Cell cycle, ROS

\section{Introduction}

Embryonic stem (ES) cells are derived from in vitro-fertilized embryos and are established using the inner cell mass of blastocysts (1). ES cells can self-renew, maintain-

Received: May 24, 2020, Revised: July 15, 2020,

Accepted: August 15, 2020, Published online: October 31, 2020

Correspondence to Younghee Lee

Department of Biochemistry, College of Natural Sciences, Chungbuk National University, 1 Chungdae-Ro, Seowon-Gu, Cheongju 28644, Korea

Tel: +82-43-261-3387, Fax: +82-43-267-2306

E-mail: yhl4177@cbnu.ac.kr

(c) This is an open-access article distributed under the terms of the Creative Commons Attribution Non-Commercial License (http://creativecommons.org/ licenses/by-nc/4.0/), which permits unrestricted non-commercial use, distribution, and reproduction in any medium, provided the original work is properly cited.

Copyright (c) 2021 by the Korean Society for Stem Cell Research ing their stemness, and have pluripotent ability of differentiation to multiple lineages under certain conditions. Understanding of the molecular mechanisms involved in the maintenance of ES cells is one of the most critical issues in stem cell biology.

Reactive oxygen species (ROS) are defined as chemically reactive chemical species containing oxygen. A certain amount of ROS is generated during cellular metabolism and has an important role in cell signaling and homeostasis (2). However, excessive ROS causes oxidative stress and induces cell damage and cell death (3). ES cells are highly proliferative cells that require robust metabolism to enhance rapid division. However, this process relies primarily on glycolysis and the pentose phosphate pathway rather than on oxidative phosphorylation (4-6). Furthermore, ES cells have higher expression of antioxidant genes than differentiated cells $(7,8)$. Therefore, ES cells have low levels of ROS, which is essential to 
maintain pluripotency.

MUC1 is a transmembrane protein that is found in various cells and controls adhesion, migration, and cell signaling (9). MUC1 is composed of an extracellular subunit and a membrane-associated subunit. The N-terminal subunit of MUC1 (MUC1-N) is heavily glycosylated and comprises most of the variable number tandem repeat region with a signal peptide sequence at the $\mathrm{N}$-terminus and the sea urchin sperm protein enterokinase and agrin (SEA) domain. The SEA domain includes an autoproteolytic cleavage site, which generates MUC1-N and MUC1-C terminal (MUC1-C) subunits soon after its translation as a single protein. MUC1-C comprises an extracellular domain (58 amino acid), a transmembrane domain (28 amino acid), and a cytoplasmic tail (72 amino acid) (10). Under normal conditions, MUC1 subunits form a heterodimeric complex on the plasma membrane by association via hydrogen bonds. However, the complex can be dissociated by additional proteolytic cleavage events and released from the cell surface.

MUC1-C interacts with various signaling molecules such as $\operatorname{STAT3}(11), \operatorname{GSK} 3 \beta$ (12), and NF- $\kappa$ B (13) and participates in their downstream signaling pathways. Furthermore, MUC1-C associates with various transcription factors and transcriptionally regulate expression of their target genes on the promoters (10). These signaling molecules are involved in the regulation of pluripotency in ES cells (14-16). However, the role of the MUC1-C regarding ES cells remains unknown. Therefore, this study aimed to check the effects of MUC1-C inhibition and draw the possible function of MUC1-C in mouse ES (mES) cells.

\section{Materials and Methods}

\section{Mouse embryonic stem cell culture}

The $\mathrm{mES}$ cell line R1 was maintained on mouse embryonic fibroblast (MEF) cells in ES medium containing Dulbecco's modified Eagle's medium (DMEM), 15\% fetal bovine serum (FBS; Hyclone Inc., Logan, UT, USA), 0.1 $\mathrm{mM} \beta$-mercaptoethanol, $0.1 \mathrm{mM}$ nonessential amino acids, $100 \mathrm{U} / \mathrm{ml}$ penicillin, and $100 \mu \mathrm{g} / \mathrm{ml}$ streptomycin (Gibco/Life Technologies, Long Island, NY, USA) at $37^{\circ} \mathrm{C}$ under a humidified atmosphere of $5 \% \mathrm{CO}_{2}$. Cells were dissociated with TrypLE Express (Gibco) and then seeded on the MEF cells prepared as follows. MEF cells were harvested, irradiated with 50 Gray, and seeded at a density of $\sim 5.5 \times 10^{4}$ cells $/ \mathrm{ml}$ in MEF medium (DMEM, $10 \%$ FBS, $0.1 \mathrm{mM} \beta$-mercaptoethanol, $0.1 \mathrm{mM}$ nonessential amino acids) a day before $\mathrm{mES}$ cell seeding.

\section{Differentiation of $\mathrm{mES}$ cells with retinoic acid}

The cells were plated on gelatin-coated six-well plates and grown overnight with Leukemia Inhibitory Factor (LIF; Peprotech, Rocky Hill, NJ, USA). To stimulate the differentiation of $\mathrm{mES}$ cells, cells in the MEF medium were treated with $10 \mu M$ retinoic acid (RA; Sigma Aldrich, St. Louis, MO, USA) for 7 days. The medium was changed every day.

\section{Flow cytometry analysis}

The expression of MUC1 was assessed by flow cytometry. The cells were fixed and permeabilized using cytofix/ cytoperm $^{\mathrm{TM}}$ (BD Biosciences, San Jose, CA, USA). After washing, the cytofix/cytoperm ${ }^{\mathrm{TM}}$ wash solution (BD Biosciences) was added to the cells together with antiMUC1 antibody (Abcam, Cambridge, MA, USA) recognizing the C-terminal domain of $\mathrm{MUCl}$ and incubated at $4^{\circ} \mathrm{C}$ overnight. The cells were washed with the cytofix/ cytoperm $^{\mathrm{TM}}$ wash solution and then incubated with the Alexa 488-labeled secondary antibody (Invitrogen, Carlsbad, CA, USA) in cytofix/cytoperm ${ }^{\mathrm{TM}}$ wash solution at $4^{\circ} \mathrm{C}$ in the dark for $1 \mathrm{hr}$. Samples were analyzed by a FACSCalibur (BD Biosciences) flow cytometer and the data were analyzed with the software FCS Express 5 (De Novo Software, Pasadena, CA, USA).

\section{Treatment with MUCl-C inhibitor peptide}

The cells were plated on gelatin-coated six-well plates and grown overnight with LIF. Cells were treated with MUC1-C inhibitor GO201 (D-RRRRRRRRR-CQCRRKN YGQLDIFP) or control peptide CP1 (D-RRRRRRRRRAQARRKNYGQLDIFP) at the indicated concentrations for $24 \mathrm{hr}$. CP1 and GO201 peptides were synthesized by Peptron Inc. (Yuseong-gu, Daejeon, Republic of Korea) as described previously (17).

\section{RT-PCR and quantitative PCR}

Total RNA was isolated using TRI Reagent ${ }^{\circledR}$ according to the manufacturer's instructions (MRC, Cincinnati, $\mathrm{OH}$, USA). $2 \mu \mathrm{g}$ of total RNA was reverse-transcribed in the first-strand buffer containing $6 \mu \mathrm{g} / \mathrm{ml}$ oligo(dT) primer, $50 \mathrm{U}$ M-MLV reverse transcriptase (Invitrogen), $2 \mathrm{mM}$ dNTP, and $40 \mathrm{U}$ RNaseOUT ${ }^{\mathrm{TM}}$ recombinant ribonuclease inhibitor (Invitrogen) at $42^{\circ} \mathrm{C}$ for $1 \mathrm{hr}$. Quantitative PCR reaction was performed using Rotor-Gene SYBR $^{\circledR}$ Green PCR Kit (Qiagen, Germany). The PCR reaction was performed at $10 \mathrm{~min}$ at $95^{\circ} \mathrm{C}$ for $1 \mathrm{cycle}, 15 \mathrm{sec}$ at $95^{\circ} \mathrm{C}$ and $20 \mathrm{sec}$ at $60^{\circ} \mathrm{C}$ for 40 cycles. The primer sequences used are as follows: qOct4, 5'-CACGAGTGGAAAGCAACTC A-3' (sense) and 5'-AGATGGTGGTCTGGCTGAAC-3' 
(antisense); qMUC1, 5'-GGTTGCTTTGGCTATCGTCTA TTT-3' (sense) and 5'-AAAGATGTCCAGCTGCCCATA-3' (antisense); qGAPDH, 5'-AACTTTGGCATTGTGGAAGG-3' (sense) and 5'-ACACATTGGGGGTAGGAACA-3' (anti-sense). Relative expression of the target gene was calculated using the $\triangle \Delta \mathrm{Ct}$ method with GAPDH as a reference control. Relative expression of the genes during differentiation (\%) was determined by dividing normalized values within a data set by the normalized arbitrary units of undifferentiated mES cells. A standard PCR reaction was performed using one microliter of the cDNA solution for $20 \sim 30$ cycles of denaturation for $60 \mathrm{sec}$ at $95^{\circ} \mathrm{C}$, annealing for $60 \mathrm{sec}$ at $58^{\circ} \mathrm{C}$, and elongation for $60 \mathrm{sec}$ at $72^{\circ} \mathrm{C}$. The primer sequences used are as follows: Oct4, 5'-CTCGA ACCACATCCTTCTCT-3' (sense) and 5'-GGCGTTCTCTT TGGAAAGGTGTTG-3' (antisense); MUC1, 5'-GCAGTGTG CCAGTGCCGCCG-3' (sense) and 5'-CAGTCCTTCTGA GAGCCACC-3' (antisense); GAPDH, 5'-ACCACAGTCCA TGCCATCAC-3' (sense) and 5'-TCCACCACCCTGTTG CTGTA-3' (anti-sense).

\section{Western blotting}

Whole cell lysates were prepared as previously described (18). Samples were separated by SDS-polyacrylamide gel electrophoresis and electro-transferred to polyvinylidene fluoride (PVDF) membranes (Millipore Corp., Billerica, MA, USA). Membranes were blocked with 5\% dry skim milk and treated with anti-Phospho-Stat3 (Tyr705), anti-Stat3 (Cell Signaling Technology, Beverly, MA, USA), anti-Oct4 (BD Biosciences), anti-MUC1 (Abcam), antiBcl2, anti-Mcl1, anti-GAPDH, and anti- $\beta$-actin (Santa Cruz Biotechnology Inc., Santa Cruz, CA, USA) antibodies. Immunoreactive proteins were visualized by horseradish peroxidase-conjugated secondary antibody (Santa Cruz Biotechnology Inc.) and an ECL reagent (ATTO Corp., Tokyo, Japan).

\section{Alkaline phosphatase assay}

Alkaline phosphatase staining was conducted using alkaline phosphatase kit 86-R (Sigma) according to the manufacturer's protocol. Briefly, cell layers were rinsed with phosphate buffer saline (PBS) and fixed with citrate-acetone-formaldehyde fixative solution $(65 \mathrm{ml}$ acetone, $0.8 \mathrm{ml}$ of $37 \%$ formaldehyde, $25 \mathrm{ml}$ citrate solution) at room temperature for $30 \mathrm{sec}$. The samples were then stained with an alkaline-dye mixture (Sodium Nitrite Solution: FRV-Alkaline Solution: Naphthol AS-BI Alkaline $=1: 1: 1)$ at room temperature for $15 \mathrm{~min}$.

\section{Cell proliferation assay}

A cell proliferation assay was conducted using Cell Proliferation ELISA, BrdU kit (Roche Diagnostics. GmbH, Mannheim, Germany) according to the manufacturer's instructions. Briefly, the cells were placed onto a 96-well plate, and incubated for $24 \mathrm{hr}$. The cells were treated with GO201 or CP1 at the indicated concentration for $24 \mathrm{hr}$. After treatment, $10 \mu \mathrm{M}$ BrdU was added to each well and incubated for $4 \mathrm{hr}$ at $37^{\circ} \mathrm{C}$. After the incubation, the growth medium was removed and cells were denaturated and fixed using FixDen for $30 \mathrm{~min}$. The fixed cells were then incubated with anti-BrdU antibody conjugated with peroxidase (anti-BrdU-POD) for $90 \mathrm{~min}$. The peroxidase substrate was added and BrdU incorporation was quantified by measuring the absorbance at $450 \mathrm{~nm}$ using an ELISA reader.

\section{Cell cycle analysis}

The cells were treated with CP1 or GO201 at $2.5 \mu \mathrm{M}$ for $24 \mathrm{hr}$, harvested, and fixed in $70 \%$ ethanol at $4^{\circ} \mathrm{C}$ overnight. The next day the fixed cells were stained with propidium iodide (PI)/RNase staining buffer (BD Biosciences) for $15 \mathrm{~min}$ and analyzed using a FACSCalibur flow cytometer (BD Biosciences). Cell debris and clumps were excluded from the analysis for all samples. The data were analyzed with the software FCS Express 5 (De Novo Software).

\section{Analysis of apoptosis (Annexin V/PI staining)}

To determine the cellular apoptosis or necrosis, we used the Annexin-V-FLUOS staining kit (Roche). The cells were dissociated with TrypLE Express, washed with PBS, and stained with Annexin-V-FLUOS labeling solution for $15 \mathrm{~min}$. The cells were then analyzed by a FACSCalibur (BD Biosciences) flow cytometer.

\section{Reactive oxygen species (ROS) measurement}

For the measurement of the intracellular ROS levels, we used an oxidation sensitive fluorescent probe, 2',7'-dichlorofluorescein diacetate (DCF-DA) (Molecular Probes, Eugene, OR, USA). Briefly, the cells were treated with GO201 or CP1 at the indicated concentrations for $24 \mathrm{hr}$. As another experiment, the cells were untreated or treated with N-acetyl-L-cysteine (NAC) at the indicated concentration for $1 \mathrm{hr}$ followed by treatment with GO201 or CP1 at the indicated concentrations for $24 \mathrm{hr}$. After treatment, the cells were incubated with $10 \mu \mathrm{M}$ DCF-DA for $30 \mathrm{~min}$ at $37^{\circ} \mathrm{C}$. Then the cells were dissociated with TrypLE Express, suspended in fresh medium, and analyzed by a FACSCalibur (BD Biosciences) flow cytometer. 


\section{Determination of glutathione (GSH) levels}

For the measurement of the intracellular glutathione levels, we used a Glutathione Colorimetric Assay Kit (BioVision Inc., Milpitas, CA, USA). The cells were harvested with ice-cold PBS and lysed in ice-cold glutathione buffer. The cell lysate was then incubated with glutathione reductase and the GSH substrate for $10 \mathrm{~min}$. The absorbance at a wavelength of $405 \mathrm{~nm}$ was measured by a microplate reader (Bio-Rad). A standard curve was obtained with known concentrations of GSH and used to quantify total GSH content in the unknown samples.

\section{Statistics}

The results are shown as the mean \pm standard deviation (SD) from at least three independent experiments. Statistical significance of the differences between two sample groups was evaluated using Student's t-test. $\mathrm{p}<0.05$ was considered statistically significant.

\section{Results}

\section{The protein level of MUCl-C was decreased during differentiation of $\mathrm{mES}$ cells}

To investigate the expression patterns of MUC1 in undifferentiated mES cells and differentiated cells, we determined the mRNA and protein levels of MUC1 during RA-induced differentiation (19) of mES cells. As shown in the results of quantitative PCR, the expression level of
MUC1 mRNA was significantly decreased on the first day of differentiation, recovered on day 3, and then increased on day 7 (Fig. 1A). On the other hand, the protein level of MUC1-C determined by western blotting was markedly decreased upon differentiation (Fig. 1B). FACS analysis also showed decreased expression of MUC1-C in the RA-differentiated cells compared to that of the untreated mES cells (Fig. 1C). Taken together, the results show that the expression level of MUC1-C protein in mES cells is higher than that of differentiated cells, suggesting that MUC1-C may be involved in the regulation of ES cells.

\section{Inhibition of $\mathrm{MUCl}-\mathrm{C}$ reduces growth of $\mathrm{mES}$ cells}

The MUC1 cytoplasmic tail is involved in the formation of MUC1 oligomers through a CQC motif (17). MUC1-C oligomerization directs its nuclear localization and interaction with various effectors. To investigate the potential role of MUC1-C in mES cells, we used a cell-permeable inhibitor peptide GO201, which contains the CQC motif, and a control peptide (CP1) in which CQC was substituted for AQA. To determine the effect of MUC1-C inhibition on the maintenance of mES cells, we treated the cells with GO201 or CP1 and monitored for colony formation and growth. Based on the colony size and numbers, GO201-treated cells showed reduced colony formation compared with CP1-treated cells. While CP1treated cells retained large and well-formed ES cell colonies, GO201-treated cells displayed a concentration-de-

A

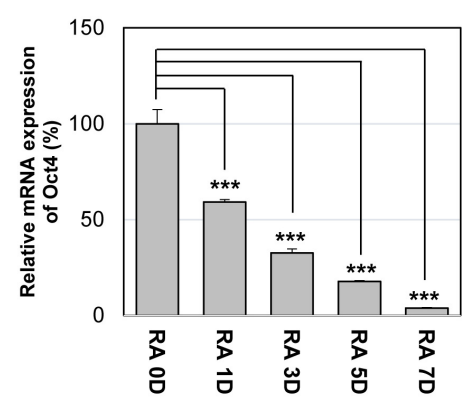

B

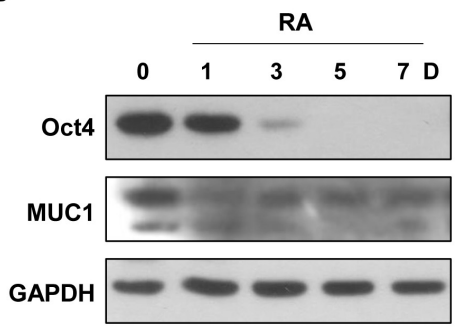

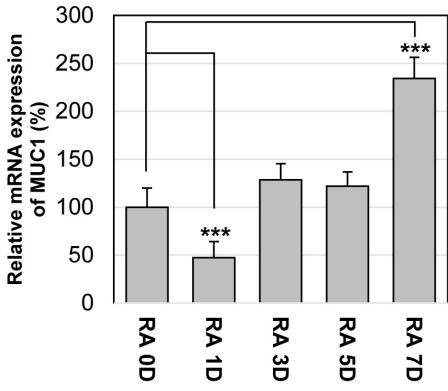

C

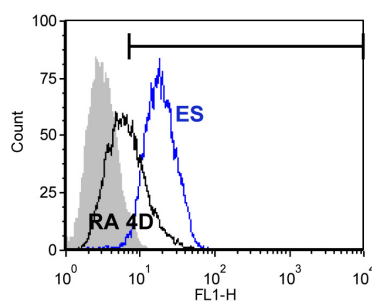

Fig. 1. Expression of $\mathrm{MUC1}$ in mouse embryonic stem (mES) cells. The cells were differentiated with retinoic acid (RA, $10 \mu \mathrm{M})$ for the indicated period. (A) The relative expression levels of Oct4 and MUC1 mRNAs were analyzed by quantitative real-time PCR. Each bar is expressed as the mean \pm standard deviation (SD) of three experiments. $* * * p<0.001$ (vs RA 0D). The protein level of MUC1-C was analyzed by western blotting (B) and flow cytometry (C). 
pendent decrease in colony size and a marked increase in cell death at $20 \mu \mathrm{M}$ (Fig. 2A).

The alkaline phosphatase assay showed that the colony size and the number of alkaline phosphatase-positive colonies were reduced by GO201 (Fig. 2B). However, the intensity of alkaline phosphatase staining showed no significant difference between the two groups. Additionally, we performed a BrdU incorporation analysis to test whether inhibition of MUC1-C affects the growth of ES cells. The results revealed that the proliferation was reduced in the $20 \mu \mathrm{M}$ GO201-treated cells compared with the CP1treated cells (Fig. 2C).

\section{Inhibition of MUCl-C does not affect pluripotency of mES cells}

MUC1-C activates various growth and survival pathways in a number of cancer cells $(11,13,20)$. As an example, MUC1-C promotes JAK1-mediated STAT3 phosphorylation by direct interaction with JAK1 and STAT3. Consequently, MUC1-C promotes transcriptional activation of STAT3 target genes including MUC1 (11). LIFmediated signaling pathways including the JAK/STAT pathway regulates the pluripotency of $\mathrm{mES}$ cells. To determine whether MUC1-C is involved in LIF signaling, we examined the effect of MUC1-C inhibitor on STAT3 activation. Serum-starved cells were incubated with CP1 or GO201 for $1 \mathrm{hr}$ and then stimulated with LIF-containing medium for various periods after stimulation. As determined by western blot analysis, the degree of STAT3 phosphorylation in GO201-treated cells was similar to those of untreated cells and control peptide-treated cells up to $2 \mathrm{hr}$ (Fig. 3A). Furthermore, there was no difference in the phosphorylation level of STAT3 during culture for three days in normal culture conditions with GO201 and CP1 at concentrations of 2.5 and $5 \mu \mathrm{M}$, which did not significantly induce cell death (Fig. 3B). Additionally, inhibition of MUC1-C did not induce changes in the mRNA and protein levels of MUC1 (Fig. 3C). These results suggest that MUC1-C is not involved in the STAT3 regulation in mES cells. Next, to examine the effect of MUC1-C inhibition on stem cell properties of mES cells, we examined expression levels of Oct4 as a pluripotency marker. There was no change in the expression level of Oct4 after treatment with GO201 or CP1 (Fig. 3D). These results suggest that the inhibition of MUC1-C in mES cells reduces cell growth without affecting the pluripotency marker expression and LIF signaling, at least within the examined time periods.

A
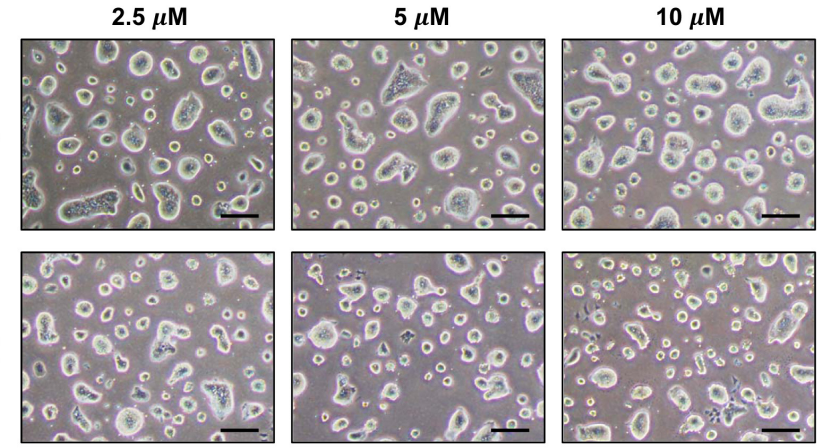

B

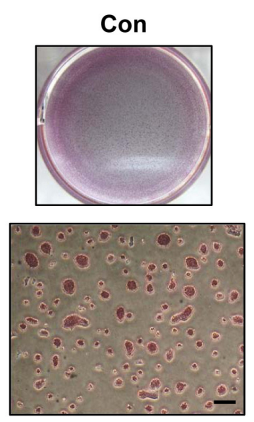

CP $20 \mu \mathrm{M}$
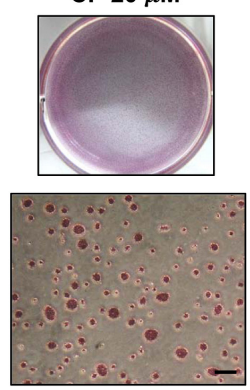

GO $20 \mu \mathrm{M}$
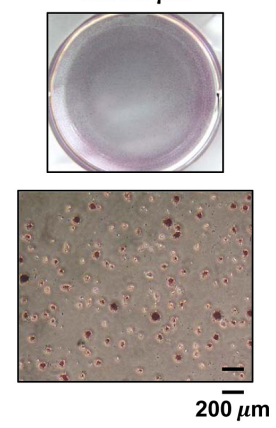

$20 \mu \mathrm{M}$
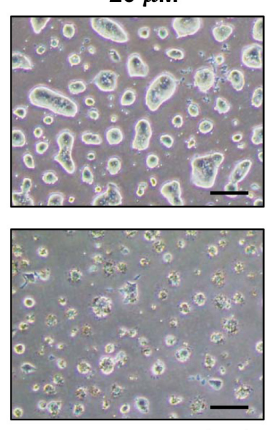

$\overline{200 \mu \mathrm{m}}$

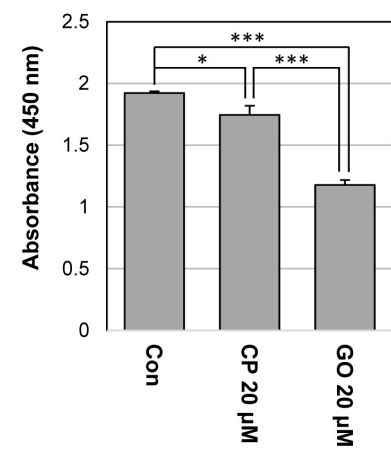

Fig. 2. Effect of MUC1-C inhibition on growth in $\mathrm{mES}$ cells. (A) Phasecontrast micrograph images of $\mathrm{mES}$ cell colonies treated with $\mathrm{CP} 1$ or $\mathrm{GO} 201$ at the indicated concentrations for $24 \mathrm{hr}$. (B) The cells were grown in the presence of $\mathrm{CP} 1$ or GO201 at the indicated concentration for $24 \mathrm{hr}$. Colonies were then stained with an alkaline phosphatase kit. (C) Cell proliferation assay was performed using Cell Proliferation ELISA, BrdU kit. The cells were treated with the indicated concentration of CP1 or GO201 for $24 \mathrm{hr}$. $\mathrm{BrdU}$ incorporation was quantified by measuring the absorbance at 450 $\mathrm{nm}$ using an ELISA reader. Each bar is expressed as the mean $\pm S D$ of three experiments. ${ }^{*} \mathrm{p}<0.05,{ }^{* * *} \mathrm{p}<$ 0.001 (vs control or CP1). Con, Control; CP, CP1; GO, GO201. 
A

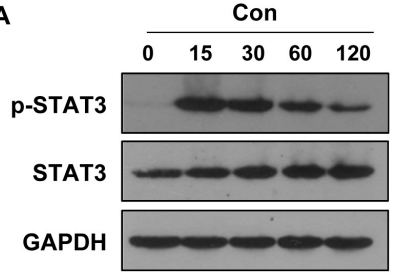

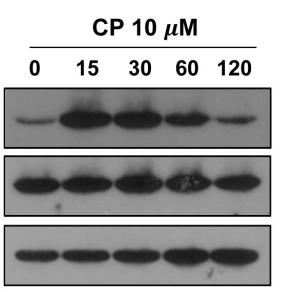

GO $10 \mu \mathrm{M}$

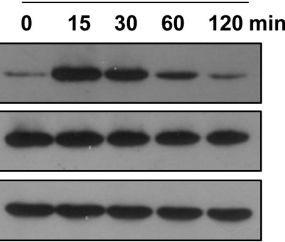

B

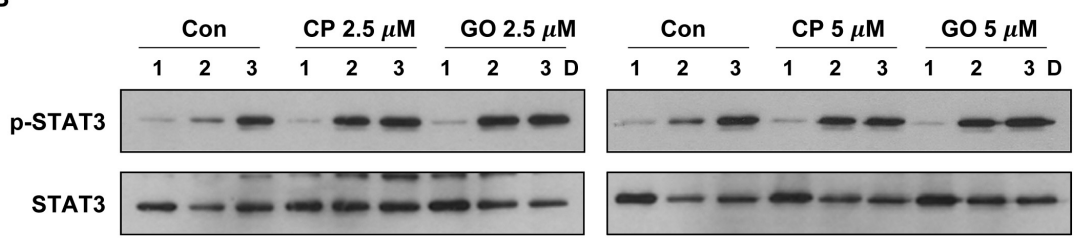

c
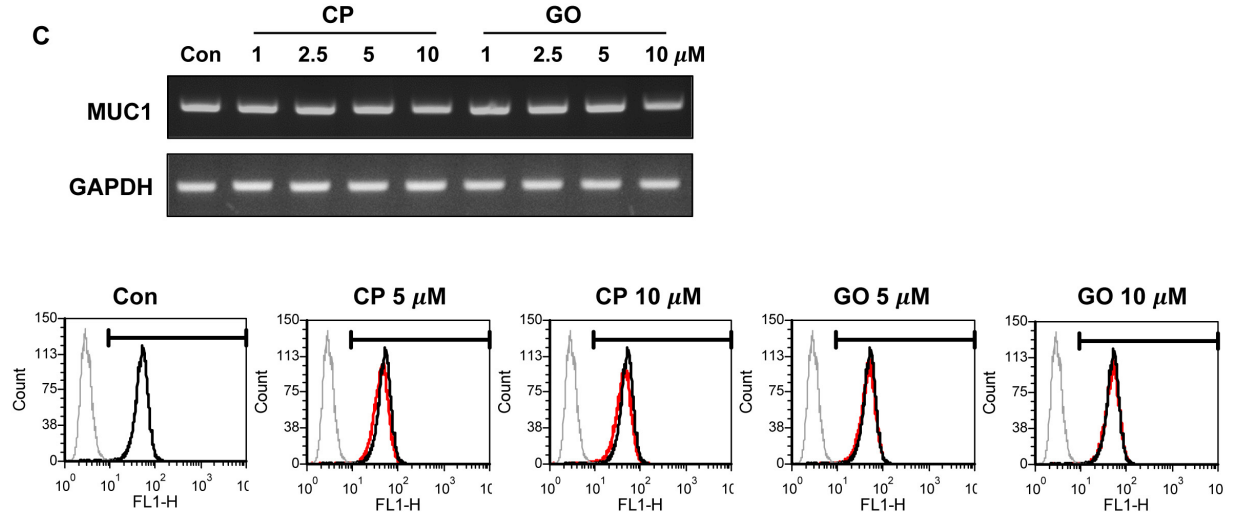

D

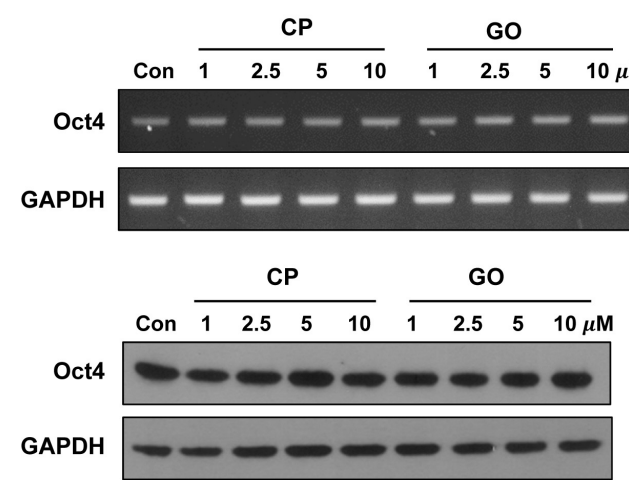

Fig. 3. Effect of MUC1-C inhibition on STAT3 signaling and expression of pluripotency marker in mES cells. (A) The cells were serum starved overnight and then preincubated for $1 \mathrm{hr}$ in the presence of $\mathrm{CP} 1$ or GO201 $(10 \mu \mathrm{M})$. They were then stimulated with FBS $(15 \%)$ and LIF for the indicated period and analyzed by western blotting. (B) The cells were treated with $\mathrm{CP} 1$ or GO201 at the indicated concentrations for three days and analyzed by western blotting. (C) The cells were treated with $\mathrm{CP} 1$ or GO201 at the indicated concentrations for $24 \mathrm{hr}$. Expression levels of MUC1 mRNA and protein were analyzed by RT-PCR (upper) and flow cytometry (lower). The histogram peak represents the expression of MUC1-C: Grey line, negative control; Black line, untreated control; Red line, CP1- or GO201treated samples. (D) The cells were treated with $\mathrm{CP} 1$ or GO201 at the indicated concentrations for $24 \mathrm{hr}$. Expression levels of Oct4 mRNA and protein were analyzed by RTPCR (upper) and western blotting (lower). Con, Control; CP, CP1; GO, GO201.

\section{Inhibition of MUC1-C induces cell cycle arrest and promotes cell death in $\mathrm{mES}$ cells}

ES cells have a specific cell cycle profile, with a short G1 phase and a high proportion of cells in S phase, which allows rapid division and proliferation of ES cells (21). To identify the mechanism of the cell growth inhibition, we performed a cell cycle analysis using the CP1- or GO201treated mES cells. The treatment with $2.5 \mu \mathrm{M}$ GO201 increased the cell population in the G1 phase and reduced the cell population in the S phase (Fig. 4A). To determine whether decreased cell growth is associated with increased apoptosis of mES cells, we performed annexin V/PI staining and found that GO201 treatment increased cell death and apoptosis of mES cells in a concentration-dependent manner (Fig. 4B). The treatment with $20 \mu \mathrm{M}$ GO201 induced a 10-fold and three-fold increase of dead cell and apoptotic cell populations, respectively, compared with 20 $\mu \mathrm{M} \mathrm{CP1}$ treatment. In addition, GO201 reduced the expression of Mcl1 and Bcl2, known as anti-apoptotic factors (Fig. 4C). These results show that the inhibition of MUC1-C induces cell cycle change and increases cell death along with reduced anti-apoptotic factor expression 
A
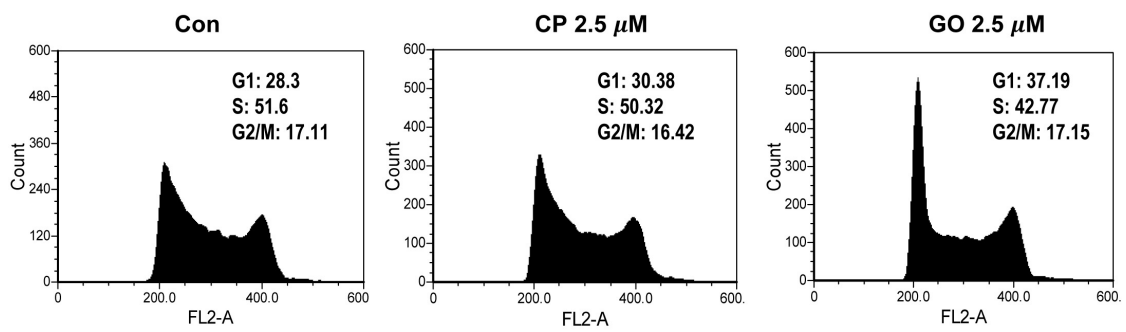

B
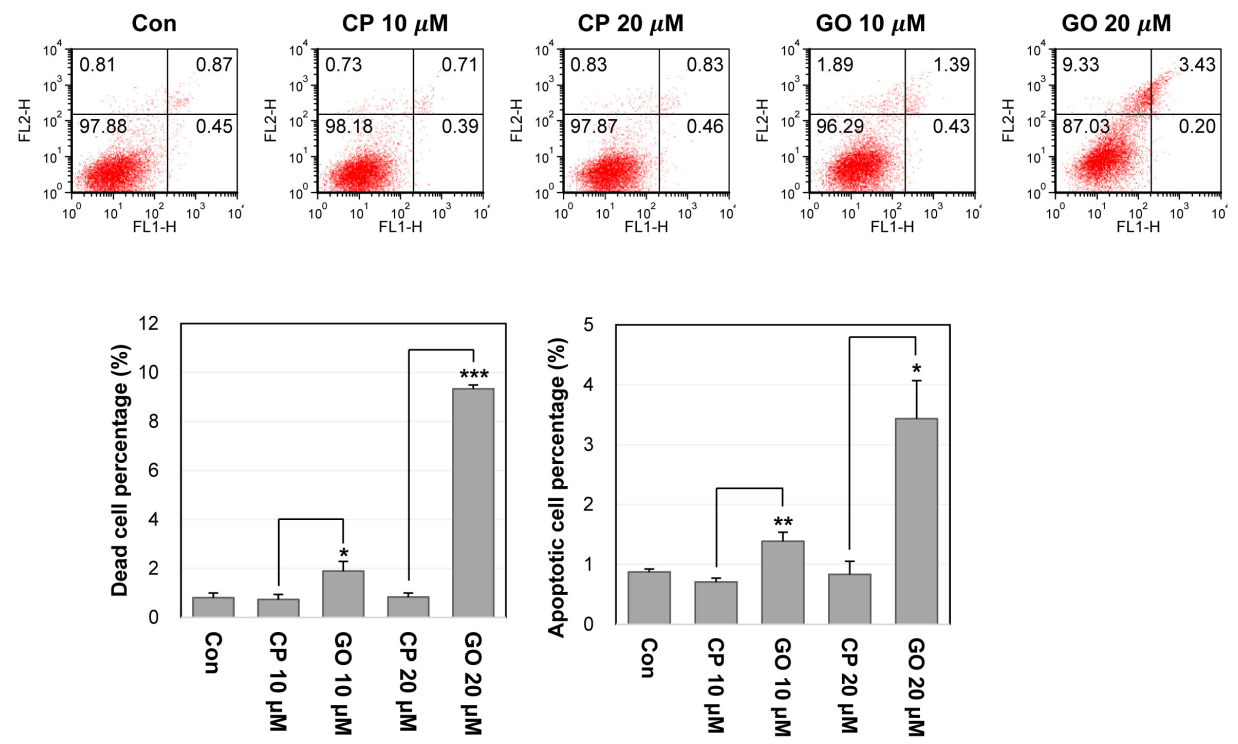

C

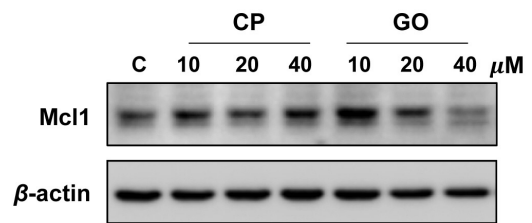

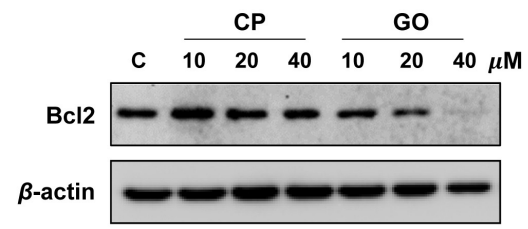

Fig. 4. Inhibition of MUC1-C induces cell cycle changes and cell death in mES cells. (A) Cell cycle analysis of mES cells by flow cytometry. The cells were treated with the indicated concentration of CP1 or GO201 for 24 hr. (B) Apoptosis of $\mathrm{mES}$ cells treated with $\mathrm{CP} 1$ or GO201 for $24 \mathrm{hr}$ was assessed by Annexin V/PI staining. Each bar is expressed as the mean $\pm \mathrm{SD}$ of three experiments. ${ }^{*} p<0.05,{ }^{* *} p<0.01$, $* * * p<0.001$ (vs CP1). The results at the bottom are shown as percentages of dead cell and apoptotic cell population. (C) Expression levels of $\mathrm{Mcl} 1$ and $\mathrm{Bcl} 2$ were analyzed by western blotting, after treatment with CP1 or GO201 at the indicated concentrations for $24 \mathrm{hr}$. Con, Control; CP, CP1; GO, GO201. in mES cells, suggesting that MUC1-C may contribute to the sustained growth and survival of mES cells.

\section{Inhibition of MUCl-C disrupts ROS balance in mES cells}

Previous studies have shown that the overexpression of MUC1 decreases intracellular ROS levels in various cancer cell lines (22). The balance of redox is one of the important factors in maintaining the characteristics of ES cells. Therefore, the change in the basal ROS level may be an important indicator for the functional state of ES cells. In this regard, ROS levels of GO201- or CP1-treated $\mathrm{mES}$ cells were assessed and the results showed that the treatment with GO201 but not CP1 increased the cellular ROS level in a concentration-dependent manner (Fig. 5A). Generally, an increased ROS level is associated with a decrease in intracellular GSH level. There was a slight increase of the GSH level in the CP-1-treated cells and the reason for this is not clear. However, the GSH level was significantly decreased by the treatment with GO201 (Fig. 5B). To further support MUC1-mediated ROS control, we tested whether the increased ROS level by GO201 treatment is restored by adding NAC, an antioxidant. As shown in Fig. 5C, the ROS level was not increased by GO201 in the presence of NAC. Furthermore, $20 \mu \mathrm{M}$ GO201-treated mES cells showed a concentration-depend- 
A

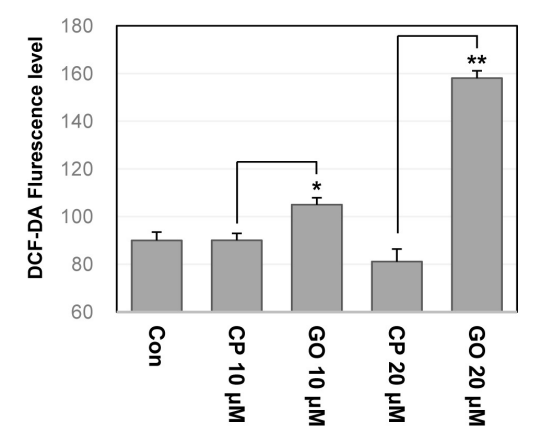

B

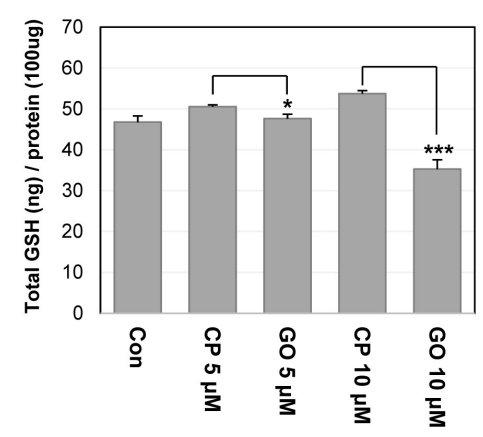

C

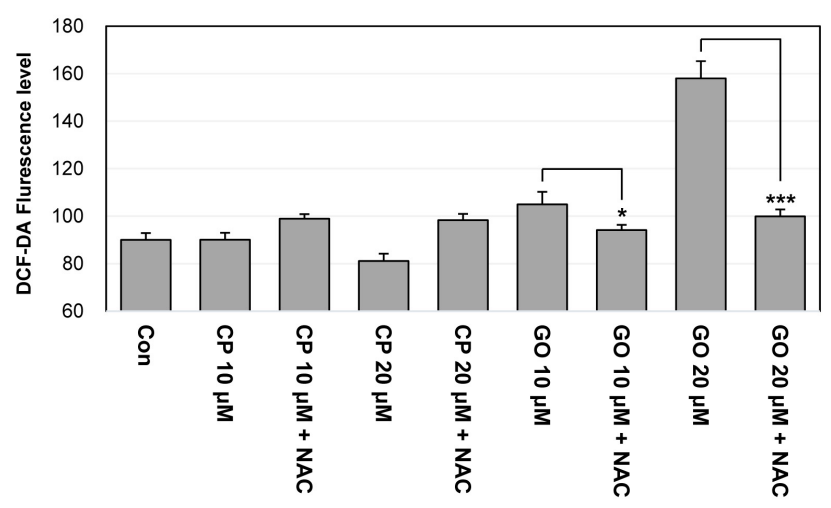

D

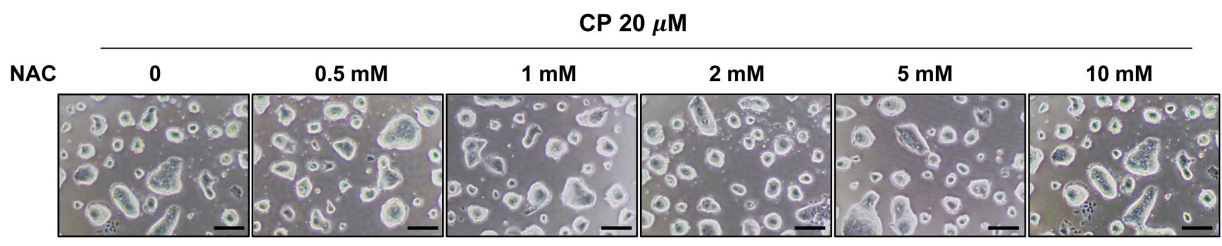

GO $20 \mu \mathrm{M}$

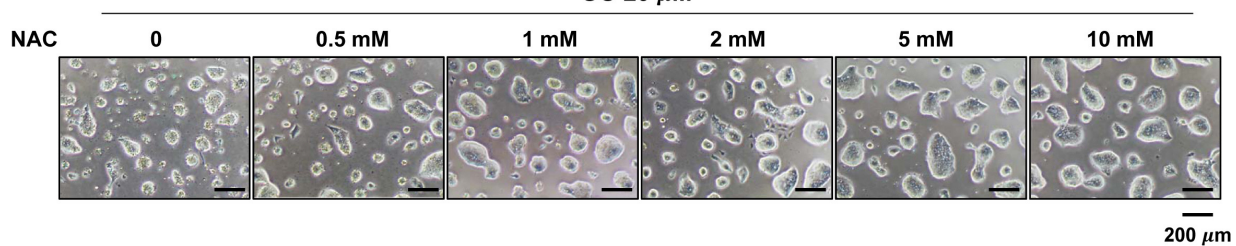

Fig. 5. MUC1-C inhibition increases ROS level in mES cells. (A) ROS level measured by flow cytometry using DCF-DA. The cells were treated with the indicated concentrations of GO201 or CP1 for $24 \mathrm{hr}$, incubated with $10 \mu \mathrm{M}$ of DCF-DA for $30 \mathrm{~min}$, and analyzed by flow cytometry. (B) The cells were treated with the indicated concentrations of GO201 or CP1 for $24 \mathrm{hr}$. The cell lysates were incubated with glutathione reductase and the GSH substrate, and the absorbance values were measured at a wavelength of $405 \mathrm{~nm}$. (C) The cells were untreated or treated with $10 \mu \mathrm{M}$ of NAC and were treated with the indicated concentrations of GO201 or CP1 for $24 \mathrm{hr}$. The cells were then incubated with $10 \mu \mathrm{M}$ of DCF-DA for $30 \mathrm{~min}$ and analyzed by flow cytometry. Each bar is expressed as the mean $\pm \mathrm{SD}$ of three experiments. ${ }^{*} \mathrm{p}<0.05,{ }^{*} \mathrm{p}<0.01$, $* * * p<0.001$ (vs CP1). (D) Images of $\mathrm{mES}$ cell colonies. The cells were untreated or treated with the indicated concentrations of NAC and were treated with $20 \mu \mathrm{M}$ of $\mathrm{GO} 201$ or CP1 for $24 \mathrm{hr}$. Con, Control; CP, CP1; GO, GO201. ent decrease of cell death and increase of colony size when NAC was added (Fig. 5D). Therefore, these results suggest that the growth inhibition and cell cycle arrest induced by inhibition of MUC1-C is associated with the change of the redox balance in mES cells.

\section{Discussion}

MUC1 is a membrane-associated glycosylated protein, which is expressed in several types of normal and cancer- ous cells. In particular, MUC1-C is overexpressed in various cancer cells, which regulates adhesion, migration, and intracellular signaling (23-28). Considering that pluripotent cells have common properties with cancer cells, it is intriguing to investigate the relevance of MUC1-C in ES cells. In this study, we investigated possible implication of MUC1-C in mES cells. We identified that MUC1-C is expressed in self-renewing mES cells and is decreased during differentiation induced by retinoic acid. These results suggest that MUC1-C may play a specific 
role in the maintenance of undifferentiated ES cells. This is consistent with the finding that the expression level of cleavage product $\mathrm{MUCl}^{*}$ is higher than that of full-length MUC1 in undifferentiated human ES cells, and it decreases as ES cell differentiation progresses (29). The human and mouse MUC1 protein sequences have only about $30 \%$ identity; the C-terminal cytoplasmic domains of MUC1, however, are highly homologous with more than $85 \%$ identity (30). Therefore, we expected that MUC1-C plays some role in the growth and maintenance of ES cells.

The results of previous studies on MUC1-C in cancer cells show that it mediates multiple roles through interaction with several signaling factors such as STAT3 (11), $\mathrm{p} 53$ (31), and $\beta$-catenin (32). To investigate the functional role of MUC1-C in mES cells, we used a cell-penetrating inhibitor peptide GO201. We found that inhibition of MUC1-C with GO201 significantly reduced the growth of $\mathrm{mES}$ cells and decreased the number of alkaline phosphatase-positive colonies. The BrdU incorporation analysis revealed that the proliferation of $\mathrm{mES}$ cells was significantly reduced by MUC1-C inhibition. To determine whether inhibition of MUC1-C affects pluripotency, we analyzed changes in specific markers of mES cells. LIF activates multiple signaling pathways such as JAK/ STAT3, PI3K/AKT, and MAPK in mES cells. Oct4 is a homeodomain transcription factor of the POU family and is essential for the self-renewal of undifferentiated embryonic stem cells (33). Inhibition of MUC1-C did not induce a change in STAT3 signaling, a representative signaling pathway of mES cells, and did not affect the expression of Oct4. These results suggest that MUC1-C may be involved in cell proliferation rather than the maintenance of pluripotency in $\mathrm{mES}$ cells.

Our next question was how inhibition of MUC1-C reduces $\mathrm{mES}$ cell growth. Previous studies have demonstrated that MUC1-C protects cells from cell death induced by various stresses $(22,34,35)$. Furthermore, it is known that MUC1-C contributes to maintaining intracellular redox balance in cancer cells. For example, Yin et al. (36) reported that MUC1-C increases the expression of antioxidant enzymes in several cancer cell lines, which protects cells from oxidative stress-induced cell death. Raina et al. (17) reported that inhibition of MUC1-C interferes with redox balance and activates a DNA damage response in human breast cancer cells. Furthermore, a number of recent studies have shown that MUC1-C regulates the expression of transcription factors involved in metabolic processes in cancer cells. Kosugi et al. (37) reported that MUC1-C binds directly to pyruvate kinase M2
(PKM2), a key enzyme in cancer metabolism, and regulates PKM2 activity. Chaika et al. (38) reported that MUC1-C induces glucose uptake and glycolysis through HIF-1 $\alpha$ regulation, and directly occupies multiple promoters of the glycolytic genes in pancreatic cancer cells. MUC1-C expression also increases the expression of glycolytic genes including hexokinase 2 (HK2) (38). Consistent with the results from cancer cells, inhibition of MUC1-C in $\mathrm{mES}$ cells induced an increase in intracellular ROS level along with a decrease in GSH level and increased cell death. Therefore, it is likely that MUC1-C plays a role in maintaining ROS levels in ES cells under normal conditions. However, inhibition of MUC1-C in mES cells did not affect the stability of HIF-1 $\alpha$ (data not shown). Although HK2 and PKM2 genes are known to regulate metabolic processes in ES cells (39), the mRNA expression levels of these genes were not changed by MUC1-C inhibition in $\mathrm{mES}$ cells (data not shown). These results suggest that MUC1-C has an ES cell-specific mechanism regulating metabolic processes. Further study on the functional role of MUC1-C will give more information regarding ES cell self-renewal and optimal conditions for the stable and efficient maintenance of ES cells.

\section{Acknowledgments}

This research was supported by grants from the National Research Foundation of Korea funded by the Ministry of Science and ICT (2017M3A9B4065302, 2018R1A2B6002504) and by the Basic Science Research Program through the NRF funded by the Ministry of Education (2019R1A6A3A 01092179) in the Republic of Korea.

\section{Potential Conflict of Interest}

The authors have no conflicting financial interest.

\section{References}

1. Evans MJ, Kaufman MH. Establishment in culture of pluripotential cells from mouse embryos. Nature 1981;292:154156

2. Devasagayam TP, Tilak JC, Boloor KK, Sane KS, Ghaskadbi SS, Lele RD. Free radicals and antioxidants in human health: current status and future prospects. J Assoc Physicians India 2004;52:794-804

3. Wang K, Zhang T, Dong Q, Nice EC, Huang C, Wei Y. Redox homeostasis: the linchpin in stem cell self-renewal and differentiation. Cell Death Dis 2013;4:e537

4. Tohyama S, Hattori F, Sano M, Hishiki T, Nagahata Y, Matsuura T, Hashimoto H, Suzuki T, Yamashita H, Satoh Y, Egashira T, Seki T, Muraoka N, Yamakawa H, Ohgino Y, Tanaka T, Yoichi M, Yuasa S, Murata M, Suematsu M, Fukuda K. Distinct metabolic flow enables large-scale puri- 
fication of mouse and human pluripotent stem cell-derived cardiomyocytes. Cell Stem Cell 2013;12:127-137

5. Zhang J, Nuebel E, Daley GQ, Koehler CM, Teitell MA. Metabolic regulation in pluripotent stem cells during reprogramming and self-renewal. Cell Stem Cell 2012;11:589595

6. Folmes CD, Dzeja PP, Nelson TJ, Terzic A. Metabolic plasticity in stem cell homeostasis and differentiation. Cell Stem Cell 2012;11:596-606

7. Saretzki G, Armstrong L, Leake A, Lako M, von Zglinicki T. Stress defense in murine embryonic stem cells is superior to that of various differentiated murine cells. Stem Cells 2004;22:962-971

8. Saretzki G, Walter T, Atkinson S, Passos JF, Bareth B, Keith WN, Stewart R, Hoare S, Stojkovic M, Armstrong L, von Zglinicki T, Lako M. Downregulation of multiple stress defense mechanisms during differentiation of human embryonic stem cells. Stem Cells 2008;26:455-464

9. Hollingsworth MA, Swanson BJ. Mucins in cancer: protection and control of the cell surface. Nat Rev Cancer 2004; 4:45-60

10. Kufe DW. Mucins in cancer: function, prognosis and therapy. Nat Rev Cancer 2009;9:874-885

11. Ahmad R, Rajabi H, Kosugi M, Joshi MD, Alam M, Vasir B, Kawano T, Kharbanda S, Kufe D. MUC1-C oncoprotein promotes STAT3 activation in an autoinductive regulatory loop. Sci Signal 2011;4:ra9

12. Huang L, Chen D, Liu D, Yin L, Kharbanda S, Kufe D. MUC1 oncoprotein blocks glycogen synthase kinase 3betamediated phosphorylation and degradation of beta-catenin. Cancer Res 2005;65:10413-10422

13. Ahmad R, Raina D, Joshi MD, Kawano T, Ren J, Kharbanda S, Kufe D. MUC1-C oncoprotein functions as a direct activator of the nuclear factor-kappaB p65 transcription factor. Cancer Res 2009;69:7013-7021

14. Niwa H, Burdon T, Chambers I, Smith A. Self-renewal of pluripotent embryonic stem cells is mediated via activation of STAT3. Genes Dev 1998;12:2048-2060

15. Ying QL, Wray J, Nichols J, Batlle-Morera L, Doble B, Woodgett J, Cohen P, Smith A. The ground state of embryonic stem cell self-renewal. Nature 2008;453:519-523

16. Kim YE, Kang HB, Park JA, Nam KH, Kwon HJ, Lee Y. Upregulation of NF-kappaB upon differentiation of mouse embryonic stem cells. BMB Rep 2008;41:705-709

17. Raina D, Ahmad R, Joshi MD, Yin L, Wu Z, Kawano T, Vasir B, Avigan D, Kharbanda S, Kufe D. Direct targeting of the mucin 1 oncoprotein blocks survival and tumorigenicity of human breast carcinoma cells. Cancer Res 2009; 69:5133-5141

18. Park JA, Kim YE, Ha YH, Kwon HJ, Lee Y. High sensitivity of embryonic stem cells to proteasome inhibitors correlates with low expression of heat shock protein and decrease of pluripotent cell marker expression. BMB Rep 2012;45:299-304

19. Stavridis MP, Collins BJ, Storey KG. Retinoic acid orchestrates fibroblast growth factor signalling to drive embryonic stem cell differentiation. Development 2010;137:881-890

20. Raina D, Kosugi M, Ahmad R, Panchamoorthy G, Rajabi H, Alam M, Shimamura T, Shapiro GI, Supko J, Kharbanda S, Kufe D. Dependence on the MUC1-C oncoprotein in non-small cell lung cancer cells. Mol Cancer Ther 2011;10: 806-816

21. White J, Dalton S. Cell cycle control of embryonic stem cells. Stem Cell Rev 2005;1:131-138

22. Yin L, Huang L, Kufe D. MUC1 oncoprotein activates the FOXO3a transcription factor in a survival response to oxidative stress. J Biol Chem 2004;279:45721-45727

23. Higashi M, Yonezawa S, Ho JJ, Tanaka S, Irimura T, Kim YS, Sato E. Expression of MUC1 and MUC2 mucin antigens in intrahepatic bile duct tumors: its relationship with a new morphological classification of cholangiocarcinoma. Hepatology 1999;30:1347-1355

24. Tamada S, Goto $M$, Nomoto $M$, Nagata $K$, Shimizu T, Tanaka S, Sakoda K, Imai K, Yonezawa S. Expression of MUC1 and MUC2 mucins in extrahepatic bile duct carcinomas: its relationship with tumor progression and prognosis. Pathol Int 2002;52:713-723

25. Singh AP, Chauhan SC, Bafna S, Johansson SL, Smith LM, Moniaux N, Lin MF, Batra SK. Aberrant expression of transmembrane mucins, MUC1 and MUC4, in human prostate carcinomas. Prostate 2006;66:421-429

26. Yonezawa S, Goto M, Yamada N, Higashi M, Nomoto $M$. Expression profiles of MUC1, MUC2, and MUC4 mucins in human neoplasms and their relationship with biological behavior. Proteomics 2008;8:3329-3341

27. Jeon JM, Lee HW, Park JY, Jung HR, Hwang I, Kwon SY, Choe MS, Kang YN, Kim SP, Lee SS, Choi WI, Kwon KY. Expression of MUC1 and MUC4 and its prognostic significance in non-small cell lung carcinoma. Korean J Pathol 2010;44:397-403

28. Jonckheere N, Van Seuningen I. The membrane-bound mucins: from cell signalling to transcriptional regulation and expression in epithelial cancers. Biochimie 2010;92:1-11

29. Hikita ST, Kosik KS, Clegg DO, Bamdad C. MUC1* mediates the growth of human pluripotent stem cells. PLoS One 2008;3:e3312

30. Spicer AP, Parry G, Patton S, Gendler SJ. Molecular cloning and analysis of the mouse homologue of the tumor-associated mucin, MUC1, reveals conservation of potential O-glycosylation sites, transmembrane, and cytoplasmic domains and a loss of minisatellite-like polymorphism. J Biol Chem 1991;266:15099-15109

31. Wei X, Xu H, Kufe D. Human mucin 1 oncoprotein represses transcription of the p53 tumor suppressor gene. Cancer Res 2007;67:1853-1858

32. Lillehoj EP, Lu W, Kiser T, Goldblum SE, Kim KC. MUC1 inhibits cell proliferation by a beta-catenin-dependent mechanism. Biochim Biophys Acta 2007;1773:1028-1038

33. Niwa H, Miyazaki J, Smith AG. Quantitative expression of Oct-3/4 defines differentiation, dedifferentiation or self-renewal of ES cells. Nat Genet 2000;24:372-376

34. Wei X, Xu H, Kufe D. Human MUC1 oncoprotein regu- 
lates p53-responsive gene transcription in the genotoxic stress response. Cancer Cell 2005;7:167-178

35. Yin L, Kharbanda S, Kufe D. MUC1 oncoprotein promotes autophagy in a survival response to glucose deprivation. Int J Oncol 2009;34:1691-1699

36. Yin L, Li Y, Ren J, Kuwahara H, Kufe D. Human MUC1 carcinoma antigen regulates intracellular oxidant levels and the apoptotic response to oxidative stress. J Biol Chem 2003;278:35458-35464

37. Kosugi M, Ahmad R, Alam M, Uchida Y, Kufe D. MUC1-C oncoprotein regulates glycolysis and pyruvate kinase M2 activity in cancer cells. PLoS One 2011;6:e28234
38. Chaika NV, Gebregiworgis T, Lewallen ME, Purohit V, Radhakrishnan P, Liu X, Zhang B, Mehla K, Brown RB, Caffrey T, Yu F, Johnson KR, Powers R, Hollingsworth MA, Singh PK. MUC1 mucin stabilizes and activates hypoxia-inducible factor 1 alpha to regulate metabolism in pancreatic cancer. Proc Natl Acad Sci U S A 2012;109:1378713792

39. Kim H, Jang H, Kim TW, Kang BH, Lee SE, Jeon YK, Chung DH, Choi J, Shin J, Cho EJ, Youn HD. Core pluripotency factors directly regulate metabolism in embryonic stem cell to maintain pluripotency. Stem Cells 2015;33: 2699-2711 